University of South Carolina

Scholar Commons

$11-19-2012$

\title{
Mechanically Robust Si Nanorod Arrays on Cu/Ti Bilayer Film Coated Si Substrate for High Performance Lithium-Ion Battery Anodes
}

Yingchao Yang

Follow this and additional works at: https://scholarcommons.sc.edu/emec_facpub

Publication Info

Published in Journal of Applied Physics, Volume 112, Issue 10, 2012, pages 103502-.

(C) Journal of Applied Physics (2012), AIP (American Institute of Physics).

Yang, Y., He, Y., Zhao, Y. \& Li, X. (2012). Mechanically Robust Si Nanorod Arrays on Cu/Ti Bilayer Film Coated Si Substrate for High Performance Lithium-Ion Battery Anodes. Journal of Applied Physics, 112 (10), 103502. http://dx.doi.org/10.1063/1.4765737

This Article is brought to you by the Mechanical Engineering, Department of at Scholar Commons. It has been accepted for inclusion in Faculty Publications by an authorized administrator of Scholar Commons. For more information, please contact digres@mailbox.sc.edu. 


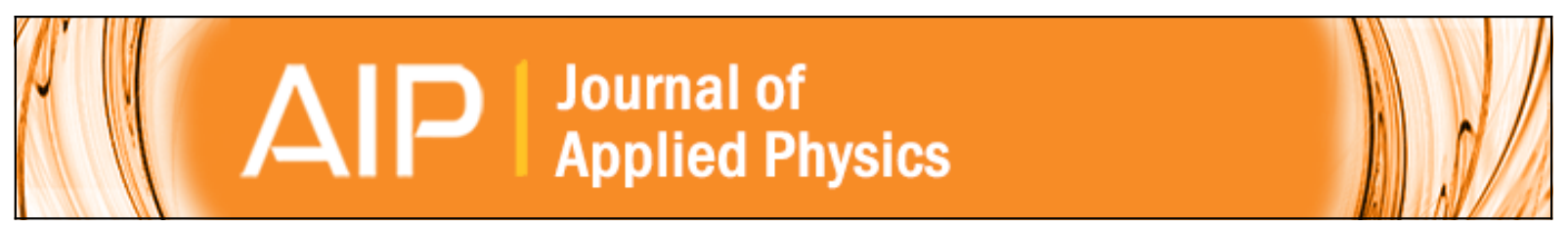

Mechanically robust Si nanorod arrays on $\mathrm{Cu} / \mathrm{Ti}$ bilayer film coated Si substrate for high performance lithium-ion battery anodes

Yingchao Yang, Yuping He, Yiping Zhao, and Xiaodong Li

Citation: Journal of Applied Physics 112, 103502 (2012); doi: 10.1063/1.4765737

View online: http://dx.doi.org/10.1063/1.4765737

View Table of Contents: http://scitation.aip.org/content/aip/journal/jap/112/10?ver=pdfcov

Published by the AIP Publishing

\section{Articles you may be interested in}

In situ cycling and mechanical testing of silicon nanowire anodes for lithium-ion battery applications

Appl. Phys. Lett. 100, 243901 (2012); 10.1063/1.4729145

Glancing angle deposition of Ge nanorod arrays on Si patterned substrates

J. Vac. Sci. Technol. A 29, 041503 (2011); 10.1116/1.3589781

Carbon-coated silicon nanowire array films for high-performance lithium-ion battery anodes

Appl. Phys. Lett. 95, 133119 (2009); 10.1063/1.3238572

High performance binderless TiO 2 nanowire arrays electrode for lithium-ion battery

Appl. Phys. Lett. 95, 113102 (2009); 10.1063/1.3224888

Silicon nanowires for rechargeable lithium-ion battery anodes

Appl. Phys. Lett. 93, 033105 (2008); 10.1063/1.2929373

AlP $\left.\right|_{\text {Letters }} ^{\text {Applied Physics }}$

is pleased to announce Reuben Collins as its new Editor-in-Chief

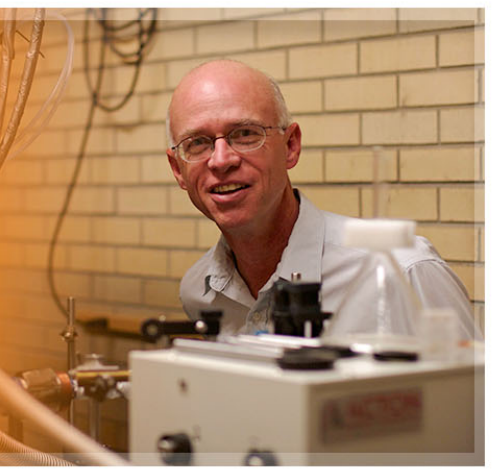




\title{
Mechanically robust Si nanorod arrays on $\mathrm{Cu} / \mathrm{Ti}$ bilayer film coated Si substrate for high performance lithium-ion battery anodes
}

\author{
Yingchao Yang, ${ }^{1}$ Yuping $\mathrm{He}^{2}{ }^{2}$ Yiping Zhao, ${ }^{2, \mathrm{a})}$ and Xiaodong $\mathrm{Li}^{1, \mathrm{a})}$ \\ ${ }^{1}$ Department of Mechanical Engineering, University of South Carolina, 300 Main Street, Columbia, \\ South Carolina 29208, USA \\ ${ }^{2}$ Department of Physics and Astronomy, and Nanoscale Science and Engineering Center, \\ University of Georgia, Athens, Georgia 30602, USA
}

(Received 28 August 2012; accepted 17 October 2012; published online 19 November 2012)

\begin{abstract}
The deformation behavior and mechanical properties of a tilted Si nanorod array structure on $\mathrm{Cu} / \mathrm{Ti}$ bilayer film coated Si substrate were studied for the first time by coupled atomic force microscopy and nanoindentation techniques. The individual $\mathrm{Si}$ nanorods fabricated by an oblique angle deposition technique are composed of many fine Si nanofibers with the diameter ranging from 10 to $50 \mathrm{~nm}$. They are not brittle, but ductile. The ductile metallic $\mathrm{Cu} / \mathrm{Ti}$ bilayer film roots contribute remarkably to the mechanical robustness of the Si nanorods. The toughening mechanism of such Si-based nanoanodes has been elucidated by experimental mechanics studies. (c) 2012 American Institute of Physics. [http://dx.doi.org/10.1063/1.4765737]
\end{abstract}

\section{INTRODUCTION}

Rechargeable lithium-ion batteries, which possess both high energy densities and high voltages, have been known as the key components for portable, computing, and telecommunication devices. ${ }^{1-3}$ Although much work has been focused on the chemical degradation of battery electrodes, mechanical failure that could cause malfuction of the entire lithium-ion battery has been largely ignored. Lack of such knowledge hinders the development of high performance lithium-ion batteries. The reliability and/or functionality of lithium-ion batteries are heavily dependent on the mechanical stability of anode materials. Cracking, pulverization, or peeling off from the underlying current collector, induced by the stress from lithium-ion insertion and extraction, can result in the loss of electrical contact and eventually fading of capacity. For example, $\mathrm{Cu}$ current collectors are widely used in lithium ion batteries to support Si based anode slurries, but they have shown poor cycling stability, even compared to Ni current collectors. ${ }^{4,5}$ To enhance the electrical conductivity and mechanical integrity of electrodes, current collectors are usually pasted by a mixture of powdery active electrode materials, conductive additives, binders, and solvent. ${ }^{6,7}$ Tailoring anode materials from bulk to aligned nanostructures on current collectors is another approach to fabricate high performance anodes for lithium-ion batteries. ${ }^{8-10}$ A simple nanofabrication technique, termed oblique angle deposition (OAD) in a thin film deposition system, has the ability to realize such nanostructures. ${ }^{11,12}$ Nevertheless, mechanical properties, which are believed to play a critical role in the function and reliability of batteries, have so far received little attention.

Atomic force microscopy (AFM) and nanoindentation have been proven to be effective tools in characterizing the

\footnotetext{
a) Authors to whom correspondence should be addressed. Electronic mail: lixiao@cec.sc.edu; zhaoy@physast.uga.edu.
}

mechanical properties of nanostructures. ${ }^{13-15}$ AFM based techniques have obtained wide applications in measuring the mechanical properties of 1D nanostructures due to the high spatial resolution and force sensing capabilities. The Hysitron triboscope nanoindenter in conjunction with AFM has been employed to perform imaging and in-situ indentation tests using a three-sided pyramidal diamond (Berkovich) indenter during indentation. Hardness and elastic modulus can be calculated from the load-displacement data. ${ }^{13,16,17}$ The target nanostructure in this study is tilted Si nanorod arrays. $\mathrm{Si}$ has been thought as the most promising candidate for the anode materials of lithium-ion batteries due to its low discharge potential and the highest theoretical charge capacity of approximately $4200 \mathrm{mAhg}^{-1}\left(\mathrm{Li}_{22} \mathrm{Si}_{5}\right){ }^{8}$, which is superior over the commercial graphite anodes, $372 \mathrm{mAhg}^{-1}\left(\mathrm{LiC}_{6}\right){ }^{18}$ However, one of the major issues with $\mathrm{Si}$ anodes is the large volume change during lithium-ion insertion and extraction, leading to cracking, consequently capacity fading and failure of the entire battery. ${ }^{19-21}$ By tuning anode materials into aligned nanostructures, lithium diffusion distance can be shorten and rate capability can be remarkably enhanced via diffusion along surface and grain boundaries, respectively. The interstitial space in-between aligned nanostructures could buffer the volume change, offering massive access sites for shuttling of Li ions, and consequently the stress associated with the expansion and contraction of anodes during electrochemical cycling would be attenuated and the cycling stability would be enhanced accordingly. ${ }^{8}$ In the past decade, a great deal of effort has already been invested in developing different morphological nanostructures, such as nanosheets, nanowires, nanotubes, and nanoparticles, to minimize electrode pulverization and capacity loss. ${ }^{22-24}$ However, to the best of our knowledge, mechanical characterization of such nanostructured anode materials is still absent in the literature.

In this study, mechanical characterization of tilted $\mathrm{Si}$ nanorod arrays grown on the $\mathrm{Cu} / \mathrm{Ti}$ bilayer film coated $\mathrm{Si}$ 
substrate by OAD was performed for the first time. Both AFM and nanoindention were employed to probe the deformation behavior and mechanical properties of such tilted nanoarray structure. The conical diamond indenter was applied to generate isotropic stress distribution during indentation. The toughening mechanism governing the mechanical robustness of the nanorod structure has been elucidated by experimental mechanics studies. We found that, from mechanics point of view, the well-aligned Si nanorod arrays on $\mathrm{Cu} / \mathrm{Ti}$ bilayer film as anode materials hold a great promise for lithium-ion battery application.

\section{EXPERIMENT}

\section{A. Si nanorod arrays fabrication}

The tilted Si nanorod arrays in a well-aligned manner were fabricated by $\mathrm{OAD}$ via electron-beam evaporation. ${ }^{12,25,26}$ In order to increase the adhesion between the Si nanorods and Si substrate, a thin layer of Ti film, $10 \mathrm{~nm}$ thick as read by a quartz crystal microbalance $(\mathrm{QCM})$, was first grown on the substrate. Then, a layer of $200 \mathrm{~nm}$ thick $\mathrm{Cu}$ film was normally deposited on the Ti film as the current collector of battery anode. After that, tilted Si nanorod arrays were grown at a vapor incident angle of $88^{\circ}$ with respect to the substrate normal to form the $\mathrm{Si} / \mathrm{Cu} / \mathrm{Ti}$ anode nanostructure.

\section{B. Nanomechanical characterization of Si nanorod arrays}

Nanoindentation (Hysitron Inc. USA) in conjunction with AFM (Veeco Metrology Group, NY, USA) was employed to characterize the mechanical properties of the obtained nanostructure by directly indenting $\mathrm{Si}$ nanorods with a conical diamond tip. The entire characterization was carried out at a controlled humidity level of less than $40 \%$ to avoid capillary effect of water condensation. ${ }^{26}$ Several tests at different locations on the Si nanorod array sample were carried out to check repeatability due to the fact that each test was inherently destructive. The indentation loads were set at $4,2,0.5,0.2$, and $0.1 \mathrm{mN}$, respectively, to analyze and compare the mutual interactions of nanorod-nanorod and nanorod-conical nanoindenter. The loading and unloading time segments were both set as $50 \mathrm{~s}$, respectively. The morphologies of the as-deposited Si nanorod array and indentation impressions were examined with scanning electron microscopy (SEM; Zeiss Ultra plus field emission gun (FEG)-SEM). Additionally, a diamond tip mounted on a stainless steel cantilever in the AFM was employed to indent individual Si nanorods to probe their mechanical response under bending. The indentation impressions were imaged insitu immediately after indentation using the same diamond tip. Elastic modulus was calculated using the initial portions of load-displacement curves.

\section{RESULTS AND DISCUSSION}

Fig. 1 shows the top-view (Fig. 1(a)) and side-view (Fig. 1(b)) SEM images of the as-deposited sample, revealing that individual $\mathrm{Si}$ nanorods are well separated from one another. From the top-view image, the number density of the nanorods is estimated to be approximately $3.4 \mathrm{rods} / \mu \mathrm{m}^{2}$, and the width $b$ of the nanorods close to their tips is $b=500$ $\pm 100 \mathrm{~nm}$. From the side-view image, the thickness $h$ and length $L$ of the nanorods are $h=110 \pm 20 \mathrm{~nm}$ and $L=3.0 \pm 0.5 \mu \mathrm{m}$, respectively, and the tilt angle $\beta$ of the nanorods is $\beta \approx 62^{\circ}$. The corresponding EDX spectra (Figs. 1(c)-1(f)) reveal the compositions of silicon substrate, $\mathrm{Ti}$ and $\mathrm{Cu}$ interlayers, and $\mathrm{Si}$ nanorod arrays, respectively. The thickness of $\mathrm{Ti}$ and $\mathrm{Cu}$ interlayer is revealed in the inset of Fig. 1(b). To probe the mechanical behavior of Si nanorod arrays, a Hysitron triboscope nanoindenter was employed to perform nanoindentation tests on the nanorod arrays. The
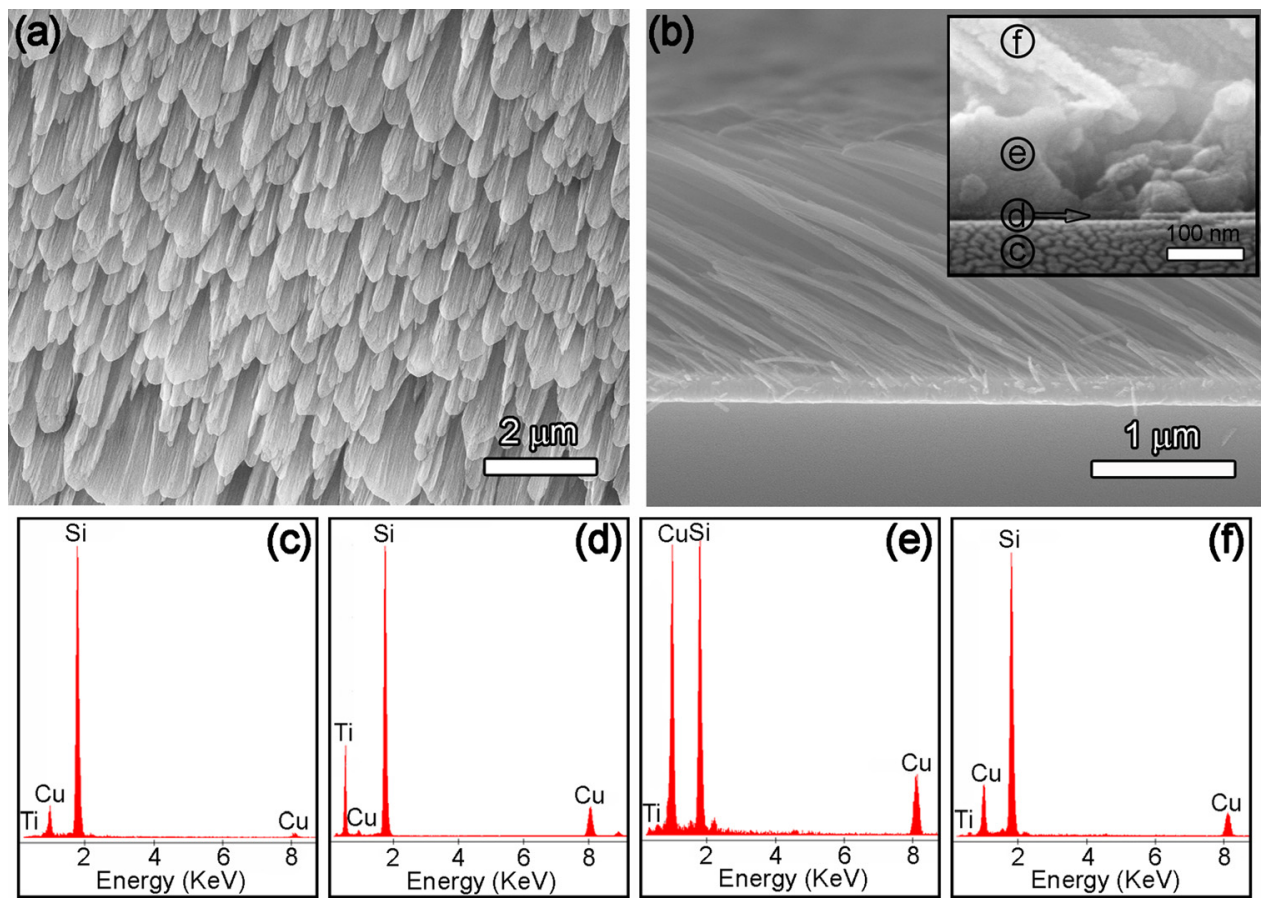

FIG. 1. SEM images and EDX spectra of Si nanorod arrays. (a) Top view, (b) side view, (c)-(f) EDX spectra of Si substrate, $\mathrm{Ti}$ interlayer, $\mathrm{Cu}$ interlayer, and Si nanorod arrays, respectively. 
nanoindenter monitors and records load and displacement during indentation. The included angle of the conical diamond nanoindenter is $120^{\circ}$. Two offsets, $3 \mu \mathrm{m}$ in both $\mathrm{X}$ and $\mathrm{Y}$ directions, were given after the indenter engagememt with the sample, in order to prevent the mutual interaction between the Si nanorods in the indenter engage location and those in following indentation impressions.

The SEM images of indentation impressions produced at different peak indentation loads together with the loaddisplacement curves are shown in Fig. 2. When an indentation load of $4 \mathrm{mN}$ was applied to indent the Si nanorod arrays, Si nanorods beneath the indenter were all smashed and the nanorods around the indent pit were also slumped, as shown in Fig. 2(a). With increasing indentation load, the Si nanorods were crushed on the substrate, the loading force continually increased to the preseted value, as shown in Fig. 2(f) $(4 \mathrm{mN})$. As peak indentation load was decreased down to $2 \mathrm{mN}$, some Si nanorods were smashed in the indent pit but others were only distorted (Fig. 2(b)). At the peak indentation load of $0.5 \mathrm{mN}$, the $\mathrm{Si}$ nanorods in and around the indent pit were twisted (Fig. 2(c)). Figs. 2(d) and 2(e) show the indent marks induced by indentations at the peak indentation loads of 0.2 and $0.1 \mathrm{mN}$, respectively. Only few Si nanorods were found to be twisted. Observing indent marks was difficult under SEM. Fig. 2(g) shows the initial portions of the load-displacement curves in Fig. 2(f). The initial portions, with displacement less than $100 \mathrm{~nm}$, were rather linear, indicating that the corresponding deformation was elastic. The steps (pop-ins) in the loading curves result from twisting of the Si nanorods, leading to the structural instability of $\mathrm{Si}$ nanorods.

Based on the above observations, three stages in the nanoindentation of tilted Si nanorod arrays appear to exist: (1) elastic deformation; (2) instability and twisting; and (3) smashing. In the first stage, the Si nanorods underneath the indenter tip were elastically deformed and the corresponding load-displacement curve is linear. In the second stage, the $\mathrm{Si}$ nanorods began to twist and fall down, leading to instability. At this stage, the surrounding nanorods supported the fallen down rods. In the final stage, some $\mathrm{Si}$ nanorods were plastically deformed, while others were smashed with fractured segements. When the indenter encountered the rigid Si substrate, the loading force increased promptly. When the loading time run out, which was set at $50 \mathrm{~s}$, the indenter began to unload. Interestingly, as a typical semiconductive material, bulk $\mathrm{Si}$ is very brittle in nature. Surprisingly, we did not find fractured Si nanorods in and around the indentation impressions under SEM, indicating that the Si nanorods are not brittle. In addition, we did not see any Si nanorods that fractured at the roots where the maximum bending stress and strain were located, suggesting that the ductile metallic $\mathrm{Cu} / \mathrm{Ti}$ bilayered roots contribute remarkably to the mechanical robustness of the Si nanorod arrays.

Previous studies ${ }^{27,28}$ have shown that $\mathrm{Cu}_{3} \mathrm{Si}$ phase in $\mathrm{Cu} / \mathrm{Si}$ composites could form through pyrolization or annealing, enhancing the $\mathrm{Cu}-\mathrm{Si}$ interfacial stability. Converting anode materials from bulk to aligned nanostructures on current collectors is another approach to improving the mechanical
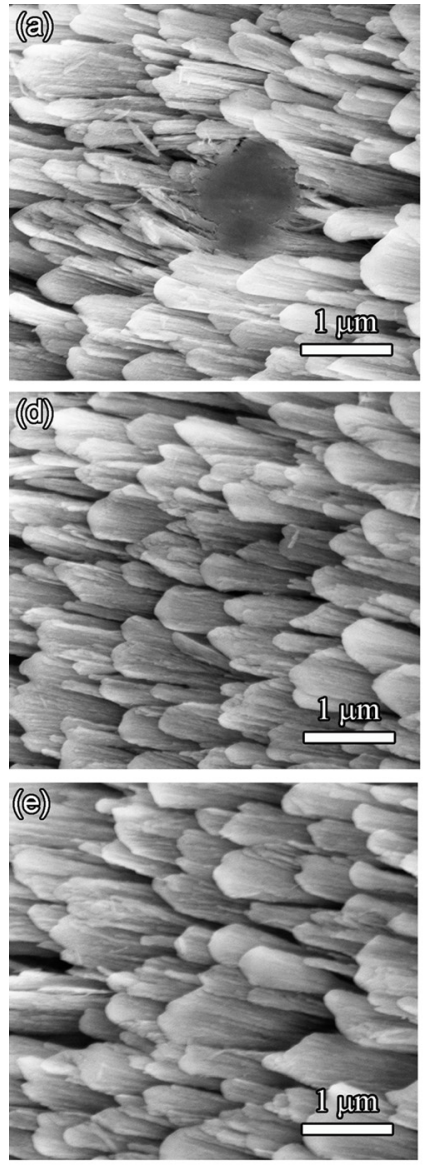
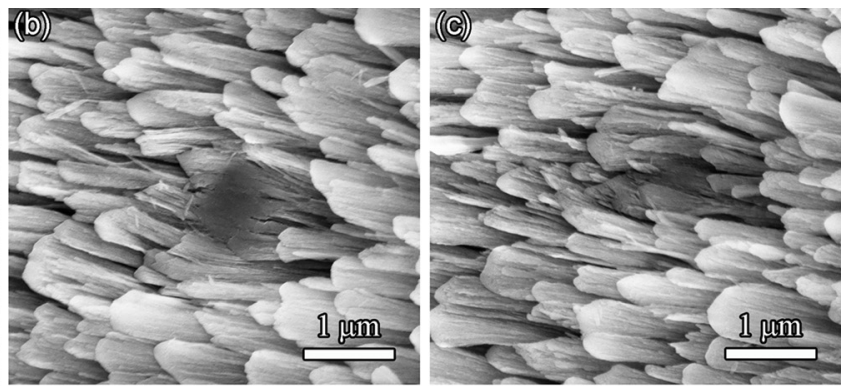

(f)

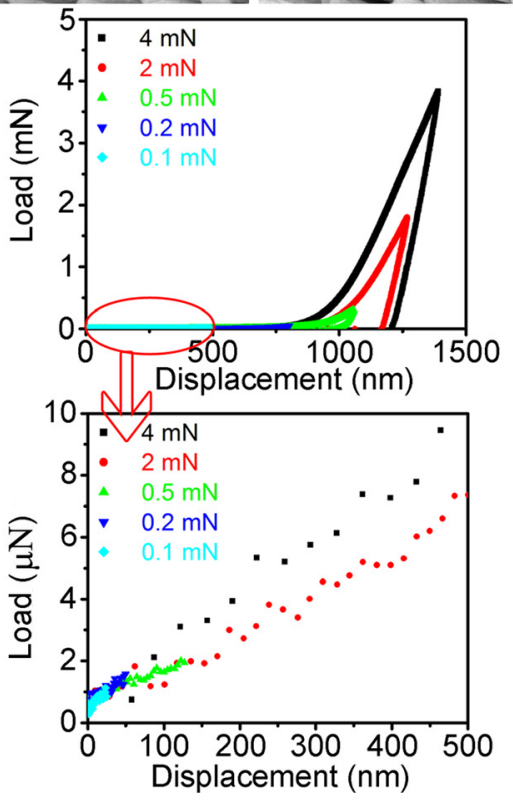

FIG. 2. SEM images of indentation impressions on tilted Si nanorod arrays and corresponding load-displacement curves. The peak indentation loads in (a), (b), (c), (d), and (e) were set at 4.0, $2.0,0.5,0.2$, and $0.1 \mathrm{mN}$, respectively. (f) Load-displacement curves. (g) Initial linear portions of the load-displacement curves in (f). 


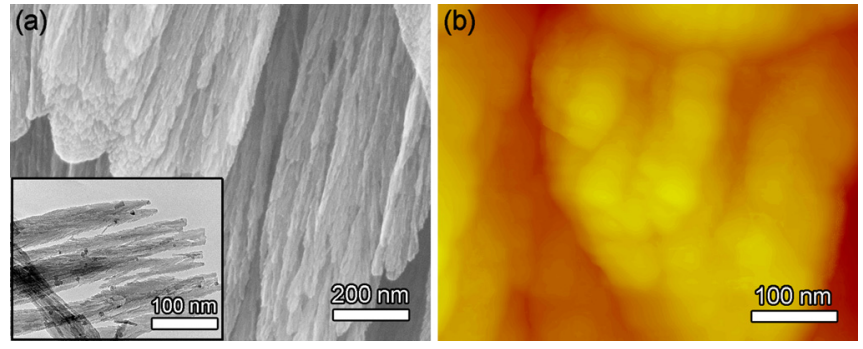

FIG. 3. SEM and TEM (a) and AFM (b) images of individual Si nanorods composed of bundles of fine Si nanofibers. The insert in (a) shows that the single Si nanorod is, in fact, composed of bundles of fine Si nanofibers.

stability. Fig. 3 shows the SEM, TEM, and AFM images of a single Si nanorod, revealing that the single Si nanorod is, in fact, composed of bundles of fine Si nanofibers with the size ranging from 10 to $50 \mathrm{~nm}$. Such hierarchical nanostructures with metallic $\mathrm{Cu} / \mathrm{Ti}$ roots are more mechanically compliant and able to buffer the volume change during lithium-ion insertion and extraction. Moreover, the interstitial space between aligned Si nanorods could accommodate the volume change and offer massive access sites for shuttling of $\mathrm{Li}$ ions. The stress associated with the expansion and contraction of anodes during electrochemical cycling can be attenuated and the cycling stability will also be enhanced. ${ }^{8,23}$ Fig. 4 shows a schematic of the morphological changes proposed for the Si nanorod arrays on $\mathrm{Cu} / \mathrm{Ti}$ bilayer film during electrochemical cycling. The $\mathrm{Li} / \mathrm{Si}$ nanorod cell was demonstrated to possess the capacity of $1500 \mathrm{mAhg}^{-1}$ in the first lithiation process. During delithiation, the $\mathrm{Si}$ structures remained the aligned fashion. ${ }^{11}$

To simulate the stress/strain variations in electrochemical cycling, mechanical cycling was performed on individual $\mathrm{Si}$ nanorods by nanoindentaion with various indentation loads. ${ }^{29}$ Fig. 5(a) shows the load-displacement curves with the indentations loads of $10,20,30,40,50,60,70,80,90$, and $100 \mu \mathrm{N}$, respectively. The individual Si nanorods exhibit excellent elastiscity. The loading curves at the higher indentation load regime could be obatined by simply extending the loading curves obtained from the lower indentation regime. The constant indentation load of $100 \mu \mathrm{N}$ was also used to run the mechanical cycling test and the corresponding
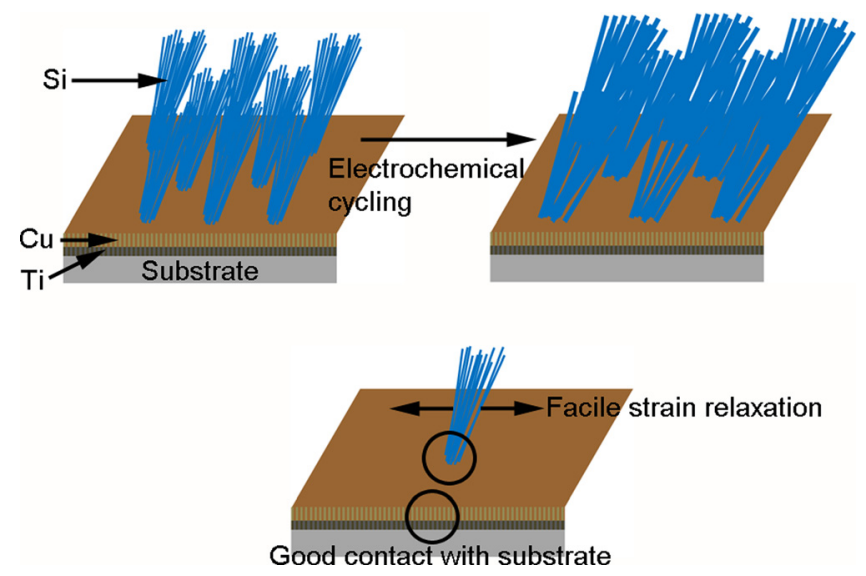

FIG. 4. Schematic of morphological changes of Si nanorod arrays on $\mathrm{Cu} / \mathrm{Ti}$ bilayer film during electrochemical cycling. load-displacement curves are shown in Fig. 5(b). All ten load-displacement curves overlap each other, indicating that the $\mathrm{Si}$ nanorod arrays on $\mathrm{Cu} / \mathrm{Ti}$ bilayer film coated on $\mathrm{Si}$ substrate have excellent mechanical cyclic stability. The target Si nanorod, pointed by the arrow in Fig. 5, was imaged using the same diamond nanoindenter tip before (Fig. 5(c)) and immediately after the 10 mechanical cyclic indentions (Fig. 5(d)). The target Si nanorod before and after the cyclic nanoindentations remianed the same morphology, validating the mechanical stability of Si nanorods.

The linear portion of the nanoindentation loaddisplacement curve obtained with the Hysitron triboscope nanoindenter was used to calculate the elastic modulus of individual $\mathrm{Si}$ nanorods. Here, we use the loading curves in Fig. 2(g) as an example. Considering the tilt nature of $\mathrm{Si}$ nanorod arrays, the loading force was decomposed into two components: one was along the axis of the nanorod, which functioned as a the buckling stress, and the other one was perpendicular to the nanorod, which represented bending stress. The mechanics equation, which correlates the vertical deflection $d$ of a slanted rod with applied force $F$ at the free end of the rod, is employed as follows: ${ }^{29,30}$

$$
d=\frac{F L^{3}(\cos \alpha)^{2}}{3 E I},
$$

where $E$ and $L$ are the Young's modulus and length of the nanorod, and $I$ is the axial moment of inertia. Equation (1) reflects the effect of the component of $F$ alone that leads to bending. Here, we simply assume that the nanorod has a rectangular cross section with respective width $b$ and thickness $h$. Then the moment of inertia can be described as

$$
I=\frac{b h^{3}}{12} .
$$

By combining Eqs. (1) and (2), the elastic modulus can be derived, which was calculated to be $90 \pm 6 \mathrm{GPa}$. The calculated value agrees well with the reported 83.9-104.3 GPa in literature. ${ }^{30-32}$ Note that the obtained elastic modulus of $\mathrm{Si}$ nanorods is lower than that of bulk Si $(165 \mathrm{GPa}),{ }^{33,34}$ but close to that of $\mathrm{Cu}(67 \mathrm{GPa})^{35}$ and $\mathrm{Ti}(110 \mathrm{GPa}){ }^{36}$ This is because the maximum bending stress and strain were located at the nanorod roots which are the metallic $\mathrm{Cu} / \mathrm{Ti}$ bilayer film with lower elastic modulus but higher mechanical deformability than Si.

In addition, the AFM with a diamond tip installed was used to indent an individual Si nanorod. Fig. 6 shows the AFM images of Si nanorod arrays before (Fig. 6(a)) and after (Fig. 6(b)) AFM indentation, respectively. The AFM tip displaced the nanorod down to $64.8 \mathrm{~nm}$, as shown in Fig. 6(c). When the target Si nanorod fell down, several Si nanorods on the falling direction were twisted, supporting the unstable $\mathrm{Si}$ nanorod. Clearly, the tilted Si nanorod arrays not only accommodate the volume change but also sustain each other in case of pulverization during lithium insertion and extraction. The elastic modulus of individual $\mathrm{Si}$ nanorods was measured by AFM to be $84 \pm 9 \mathrm{GPa}$, which is close to the value obained by nanoindentation using the Hysitron triboscope nanoindenter. 

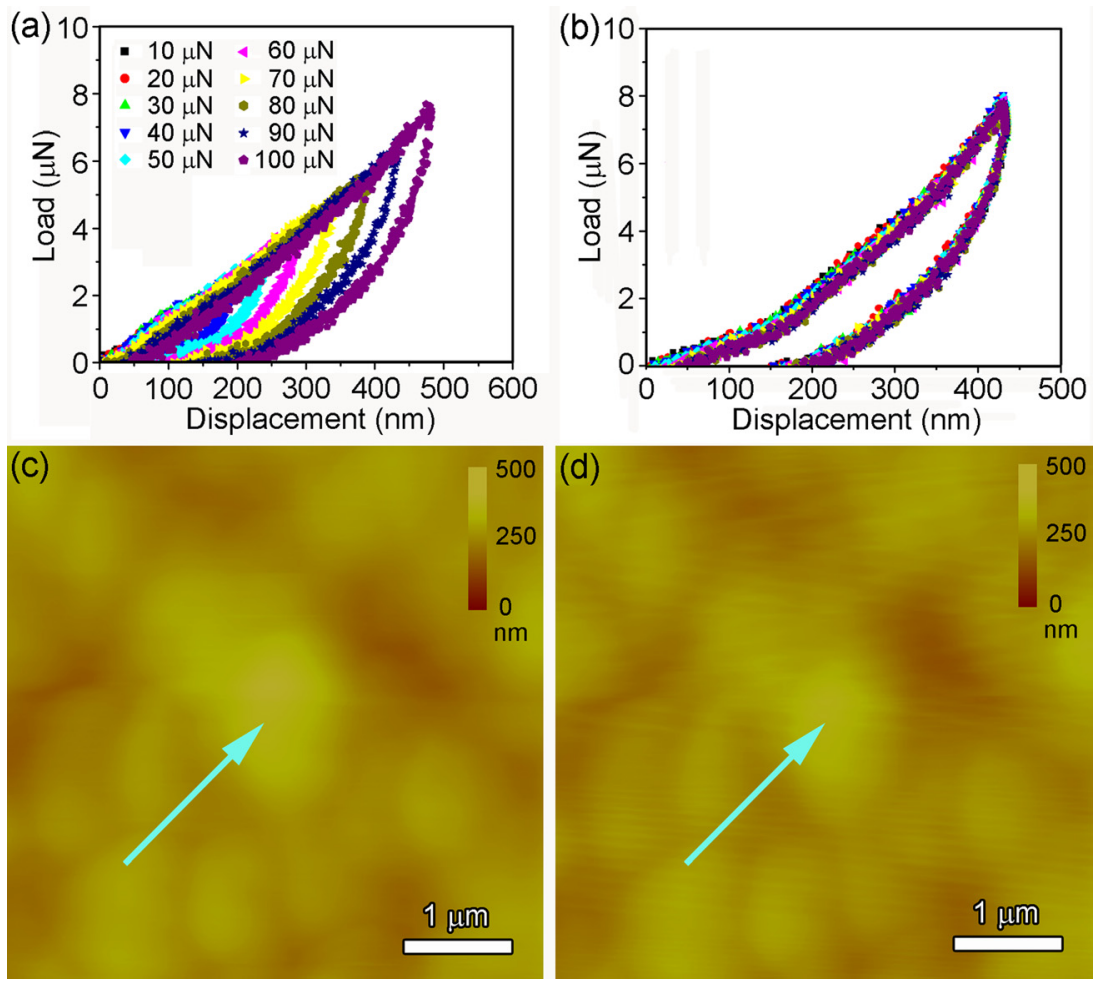

FIG. 5. Mechanical cycling by nanoindetation. (a) Load-displacement curves with the indentation loads of $10,20,30,40,50,60,70,80,90$, and $100 \mu \mathrm{N}$, respectively. (b) Load-displacement curves with $100 \mu \mathrm{N}$ indentation load for 10 cycles. (c) and (d) AFM images of $\mathrm{Si}$ nanorods before and after cyclic nanoindentations with $100 \mu \mathrm{N}$ indentation load for 10 cycles.

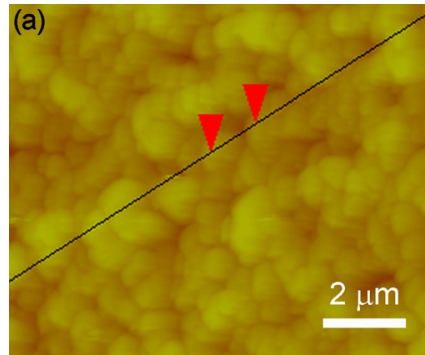

(c)
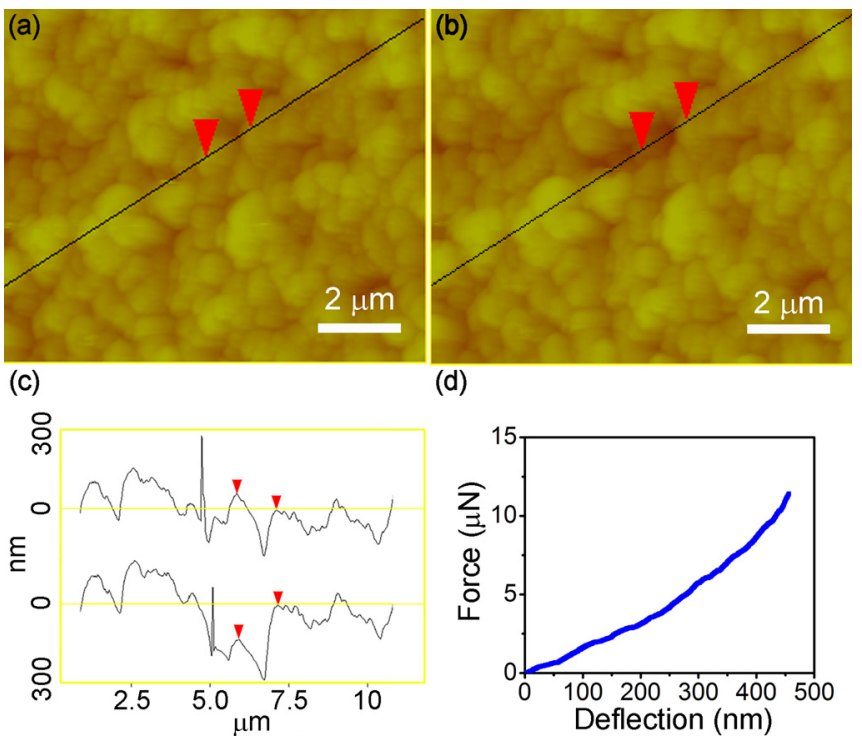

(d)

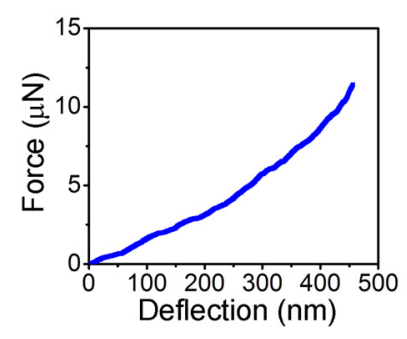

FIG. 6. Deformation behavior of Si nanorod arrays. (a) and (b) AFM images of Si nanorod arrays before and after indentation, respectively. (c) Comparison of displacement change of an individual Si nanorod in (a) and (b). (d) Applied load-deflection curve of the AFM indentation on Si nanorod.

\section{CONCLUSIONS}

The deformation behavior and mechanical properties of tilted $\mathrm{Si}$ nanorods on $\mathrm{Cu} / \mathrm{Ti}$ bilayer film were studied for the first time by coupled AFM and nanoindentation techniques. The individual Si nanorods fabricated by OAD are composed of many fine Si nanofibers with the size ranging from 10 to $50 \mathrm{~nm}$. They are not brittle, but ductile. The ductile metallic $\mathrm{Cu} / \mathrm{Ti}$ bilayered roots contribute remarkably to the mechanical robustness of the Si nanorod arrays. The interstitial space between aligned $\mathrm{Si}$ nanorods accommodates the volume change. The stress associated with the expansion and contraction of anodes during electrochemical cycling would be attenuated. Such hierarchical nanostructured $\mathrm{Si} / \mathrm{Cu} / \mathrm{Ti}$ anodes can dissipate energy and volume change in lithiumion insertion and extraction. From mechanics point of view, the well-aligned $\mathrm{Si}$ nanorod arrays on $\mathrm{Cu} / \mathrm{Ti}$ bilayer film as anode materials hold a great promise in lithium-ion batteries.

\section{ACKNOWLEDGMENTS}

Financial support for this study was provided by the U.S. National Science Foundation (CMMI-1129979, CMMI0968843, and CMMI- 0824728) and the U.S. Army Research Office under Agreement/Grant No. W911NF-07-1-0320. The authors would like to thank the staff members at the University of South Carolina EM Center for technical support.

${ }^{1}$ J. M. Tarascon and M. Armand, Nature 414, 359 (2001).

${ }^{2}$ A. Magasinski, P. Dixon, B. Hertzberg, A. Kvit, J. Ayala, and G. Yushin, Nature Mater. 9, 353 (2010).

${ }^{3}$ K. Xu, Chem. Rev. 104, 4303 (2004).

${ }^{4}$ M. Yoshio, T. Tsumura, and N. Dimov, J. Power Sources 146, 10 (2005).

${ }^{5}$ M. Uehara, J. Suzuki, K. Tamura, K. Sekine, and T. Takamura, J. Power Sources 146, 441 (2005).

${ }^{6}$ I. Boyano, M. Bengoechea, I. de Meatza, O. Miguel, I. Cantero, E. Ochoteco, J. Rodriguez, M. Lira-Cantu, and P. Gomez-Romero, J. Power Sources 166, 471 (2007).

${ }^{7}$ B. Lestrie, S. Bahri, I. Sandu, L. Roue, and D. Guyomard, Electrochem. Commun. 9, 2801 (2007).

${ }^{8}$ C. K. Chan, H. L. Peng, G. Liu, K. McIlwrath, X. F. Zhang, R. A. Huggins, and Y. Cui, Nat. Nanotechnol. 3, 31 (2008).

${ }^{9}$ N. C. Li, C. R. Martin, and B. Scrosati, J. Power Sources 97-98, 240 (2001).

${ }^{10}$ K. Kang, H. S. Lee, D. W. Han, G. S. Kim, D. Lee, G. Lee, Y. M. Kang, and M. H. Jo, Appl. Phys. Lett. 96, 053110 (2010).

${ }^{11}$ M. Au, Y. P. He, Y. P. Zhao, H. Ghassemi, R. S. Yassar, B. Garcia-Diaz, and T. Adams, J. Power Sources 196, 9640 (2011).

${ }^{12}$ Y. P. He and Y. P. Zhao, Cryst. Growth Des. 10, 440 (2010). 
${ }^{13}$ X. Y. Tao, J. Du, Y. C. Yang, Y. P. Li, Y. Xia, Y. P. Gan, H. Huang, W. K. Zhang, and X. D. Li, Cryst. Growth Des. 11, 4422 (2011).

${ }^{14}$ Y. C. Yang, G. F. Wang, and X. D. Li, Nano Lett. 11, 2845 (2011).

${ }^{15}$ Z. J. Gu, Y. C. Yang, K. Y. Li, X. Y. Tao, G. Eres, J. Y. Howe, L. T. Zhang, X. D. Li, and Z. W. Pan, Carbon 49, 2475 (2011).

${ }^{16}$ Y. C. Yang, Z. H. Xu, Z. W. Pan, and X. D. Li, Adv. Mater. 24, 881 (2012).

${ }^{17}$ X. Y. Tao, J. Du, Y. P. Li, Y. C. Yang, Z. Fan, Y. P. Gan, H. Huang, W. K. Zhang, L. X. Dong, and X. D. Li, Adv. Energy Mater. 1, 534 (2011).

${ }^{18}$ J. R. Dahn, T. Zheng, Y. H. Liu, and J. S. Xue, Science 270, 590 (1995).

${ }^{19}$ K. M. Shaju, F. Jiao, A. Debart, and P. G. Bruce, Phys. Chem. Chem. Phys. 9, 1837 (2007).

${ }^{20}$ J. W. Hall, N. Membreno, J. Wu, H. Celio, R. A. Jones, and K. J. Stevenson, J. Am. Chem. Soc. 134, 5532 (2012).

${ }^{21}$ L. W. Ji and X. W. Zhang, Energy Environ. Sci. 3, 124 (2010).

${ }^{22}$ D. Rangappa, K. D. Murukanahally, T. Tomai, A. Unemoto, and I. Honma, Nano Lett. 12, 1146 (2012).

${ }^{23}$ J. R. Szczech and S. Jin, Energy Environ. Sci. 4, 56 (2011).

${ }^{24}$ P. Meduri, C. Pendyala, V. Kumar, G. U. Sumanasekera, and M. K. Sunkara, Nano Lett. 9, 612 (2009).
${ }^{25}$ Y. He, J. G. Fan, and Y. P. Zhao, Cryst. Growth Des. 10, 4954 (2010).

${ }^{26}$ J. G. Park, S. H. Lee, B. Kim, and Y. W. Park, Appl. Phys. Lett. 81, 4625 (2002).

${ }^{27}$ J. H. Kim, H. Kim, and H. J. Sohn, Electrochem. Commun. 7, 557 (2005).

${ }^{28}$ J. W. Kim, J. H. Ryu, K. T. Lee, and S. M. Oh, J. Power Sources 147, 227 (2005).

${ }^{29}$ C. Gaire, D. X. Ye, T. M. Lu, G. C. Wang, and R. C. Picu, J. Mater. Res. 23, 328 (2008).

${ }^{30}$ C. Gaire, D. X. Ye, F. Tang, R. C. Picu, G. C. Wang, and T. M. Lu, J. Nanosci. Nanotechnol. 5, 1893 (2005).

${ }^{31}$ Y. H. Jing and Q. Y. Meng, Physica B 405, 2413 (2010).

${ }^{32}$ R. E. Rudd and B. Lee, Mol. Simul. 34, 1 (2008).

${ }^{33}$ X. D. Li, B. Bhushan, K. Takashima, C. W. Baek, and Y. K. Kim, Ultramicroscopy 97, 481 (2003).

${ }^{34}$ X. D. Li and B. Bhushan, Wear 220, 51 (1998).

${ }^{35}$ A. Luque, J. Aldazabal, J. M. Martinez-Esnaola, and J. G. Sevillano, Fatigue Fract. Eng. Mater. Struct. 29, 615 (2006).

${ }^{36}$ Y. Song, R. Yang, D. Li, Z. Q. Hu, and Z. X. Guo, J. Comput.-Aided Mater. Des. 6, 355 (1999). 